\title{
FAKTOR RISIKO KEHAMILAN PADA KEJADIAN PERDARAHAN POST PARTUM DI RUMAH SAKIT KHUSUS DAERAH IBU DAN ANAK (RSKDIA) SITI FATIMAH MAKASSAR
}

\author{
Khusnul Amirah, Suriani. B, Ros Rahmawati \\ Politeknik Kesehatan Kementerian Kesehatan Makassar \\ Email: Khusnulamirah2630@yahoo.com
}

\begin{abstract}
ABSTRAK
Perdarahan post partum adalah perdarahan yang melebihi $500 \mathrm{ml}$ setelah bayi lahir, perdarahan dalam bidang obstetric hampir selalu berakibat fatal bagi seorang ibu. Perdarahan yang paling banyak menyebabkan kematian yang memicu terjadinya perdarahan post partum diantaranya yaitu, umur, paritas dan jarak kehamilan. Penelitian ini bertujuan untuk mengetahui pengaruh faktor risiko kehamilan terhadap kejadian perdarahan post partum di RSKDIA Siti Fatimah Makassar Tahun 2018 dengan metode pendekatan case control study. Subyek penelitian ini adalah sebagian dari populasi ibu bersalin di RSKDIA Siti Fatimah Makassar sebesar 1039 orang diperoleh sampel kasus sebanyak 31 orang mengalami perdarahan post partum dan sampel kontrol sebanyak 31 orang yang tidak mengalami perdarahan post partum dengan perbandingan $1: 1$. Hasil penelitian didapatkan bahwa nilai $p=0,042<$ dari $\alpha=0,05$ dan nilai $O R>1$, menunjukkan bahwa umur $<20$ dan $>35$ tahun terdapat hubungan dan memiliki risiko 2,879 kali lebih besar untuk mengalami perdarahan post partum dibandingkan dengan umur ibu yang tidak berisiko 20-35 tahun. Paritas $>3$ didapatkan bahwa nilai $p=0,005<$ dari $\alpha=0,05$ dan nilai $O R>1$ yang berarti paritas $>3$ terdapat hubungan dan memiliki risiko 4,410 kali lebih besar untuk mengalami perdarahan post partum dibandingkan dengan paritas tidak berisiko 1-3 kali. Jarak kehamilan $<2$ tahun didapatkan bahwa nilai $p=0,005<$ dari $\alpha=0,05$ dan $O R>1$ yang berarti jarak kehamilan $<2$ tahun terdapat hubungan dan memiliki risiko 4,747 kali lebih besar untuk mengalami perdarahan post partum dibandingkan dengan jarak kehamilan $\geq 2$ tahun
\end{abstract}

Kata Kunci: Jarak Kehamilan, Umur, Paritas, Perdarahan Post Partum.

\section{ABSTRACT}

Post partum bleeding is bleeding that exceeds $500 \mathrm{ml}$ after the baby is born, bleeding in the obstetric field is almost always fatal for a mother. The bleeding that most causes death which triggers the occurrence of post partum bleeding including, age, parity and distance of pregnancy. This study aims to determine the effect of risk factors on the incidence of post partum hemorrhage in Hospital Mother and Child Siti Fatimah Makassar in 2018 with a case control study approach. The subject of this study is that a portion of the maternal population in Hospital Mother and Child Siti Fatimah Makassar amounted to 1039 people, obtained a sample of cases as many as 31 people experienced post partum hemorrhage and a control sample of 31 people who did not experience post partum hemorrhage with a ratio of 1: 1. The results showed that the value of $p=0.042<$ of $\alpha=0.05$ and OR> 1, indicating that age $<20$ and $>35$ years had a relationship and had a risk of 2.879 times greater for postpartum hemorrhage compared to the age of mothers who did not risk of 20-35 years. Parity $>3$ found that the value of $p=0.005<$ of $\alpha=0.05$ and the value of OR> 1 means parity $>3$ has a relationship and has a risk of 4.410 times greater to experience post partum hemorrhage compared to parity not at risk 1-3 times. The distance of pregnancy $<2$ years was found that the value of $p=0.005<$ of $\alpha=0.05$ and $O R>1$, which means that the pregnancy distance $<2$ years has a relationship and has a risk of 4.747 times greater for post partum hemorrhage compared to a pregnancy distance of $\geq 2$ years

Keywords: Pregnancy Distance, Age, Parity, Post Partum Bleeding.

\section{PENDAHULUAN}

Perdarahan post partum merupakan penyebab utama kematian ibu, semua wanita hamil pada saat bersalin memiliki risiko perdarahan post partum, walaupun angka kematian maternal turun secara drastis di negara-negara berkembang, perdarahan post partum tetap merupakan penyebab kematian maternal terbanyak di dunia.

$\begin{array}{crrr}\text { Menurut data } & \text { World } & \text { Health } \\ \text { Organization } & \text { (WHO) tahun } 2015\end{array}$ menunjukkan bahwa angka kematian ibu diakibatkan karena komplikasi terkait kehamilan atau persalinan diseluruh dunia setiap harinya sangat tinggi sekitar 830 per 100.000 kelahiran hidup. Menurut data UNICEF (United Nations Children's Fund) tahun 2015 AKI di Indonesia mencapai 126 per 100.000 kelahiran hidup.

Hasil Survei Demografi dan Kesehatan Indonesia (SDKI) tahun 2017, angka kematian ibu di Indonesia sebesar 277 per 100.000 kelahiran hidup. Angka ini turun jika dibandingkan tahun 2015 yaitu 305 per 100.000 kelahiran hidup. Target global SDGs (Sustainable Development Goals) tahun 2030 adalah menurunkan 
Angka Kematian lbu (AKI) menjadi 70 per 100.000 kelahiran hidup. Menurut profil kesehatan Indonesia tahun 2017 empat penyebab kematian ibu terbesar perdarahan $27,1 \%$, hipertensi dalam kehamilan sebesar $22,1 \%$, penyebab lain sebesar $30,2 \%$ (Kementrian kesehatan RI, 2017).

Data AKI di provinsi Sulawesi selatan tahun 2015, terdapat 153 kematian ibu dari $148.543(103,00 / 100.000 \mathrm{KH})$ diantaranya terdapat $47(30,71 \%)$ kematian ibu hamil, $44(27,45 \%)$ kematian ibu bersalin, dan $62(40,52 \%)$ kematian ibu nifas. (Profil Kesehatan Provinsi Sul-sel, 2016).

AKI tahun 2015 di kota Makassar, mengalami fluktuasi selama 3 tahun terakhir yaitu pada tahun 2015 sebanyak 5 kematian ibu $(19,86 \%)$ dari 25.181 kelahiran hidup (AKI : 19,86/100.000 KH). Jumlah kematian ibu tahun 2014 sama dengan tahun 2015 yaitu 5 kematian ibu $(20,33 \%)$, tapi berbeda pada kelahiran hidup yaitu 24.590 (AKI: 20,33/100.000 KH). Tahun 2013 terdapat 4 kematian ibu $(16,28 \%)$ dari 24.576 kelahiran hidup (AKI: 16,28/100.000 KH). (Profil Kesehatan Kota Makassar, 2015)

Menurut hasil penelitian Heni Anggriani (2016), faktor-faktor yang berhubungan dengan perdarahan post partum pada ibu bersalin di RSUD Pringsewu Tahun 2016, menunjukkan bahwa pada atonia uteri $\rho$-value $=0,009$ $(0,009<0,05)$. OR $=7,296$ kali lebih besar untuk mengalami perdarahan post partum, pada retensio plasenta $\rho$-value $=0,000$ $(0,000<0,05)$. OR $=13,788$ kali lebih besar untuk mengalami perdarahan post partum, dan pada laserasi jalan lahir $\rho$-Value $=0,000$ $(0,000<0,05)$. OR $=9,118$ kali lebih besar mengalami perdarahan post partum. Maka dapat disimpulkan bahwa Ha diterima ada hubungan antara variabel independen dan variabel dependen.

Data yang didapatkan dari hasil pencatatan dan pelaporan di RSKDIA Siti Fatimah Makassar tahun 2018 sebanyak 31 orang dengan kejadian perdarahan post partum disebabkan oleh atonia uteri sebanyak 2 orang $(6,45 \%)$, rest plasenta sebanyak 4 orang $(12,9 \%)$, retensio plasenta sebanyak 8 orang $(25,8 \%)$ dan laserasi jalan lahir sebanyak 17 orang (54,8\%). (Rekam Medis RSKDIA Siti Fatimah Makassar 2018).

Tujuan penelitian adalah Untuk mengetahui faktor risiko yang menyebabkan perdarahan post partum di RSKDIA Siti
Fatimah Makassar Tahun 2018.

Faktor-faktor yang mempengaruhi terjadinya perdarahan pasca persalinan, menunjukkan bahwa didapatkan nilai $\mathrm{p}=0,001$ dan $\mathrm{OR}=3,589$ dengan $95 \% \mathrm{Cl}$ :1,764-7,301, hail ini berarti bahwa ibu bersalin dengan umur berisiko berpeluang mengalami perdarahan post partum 3,589 kali lebih besar dibandingkan dengan ibu bersalin yang berumur tidak berisiko (Psiari, 2017)

Menurut hasil penelitian Juwita Anis Maryam (2017), Hubungan antara paritas dan umur ibu dengan kejadian perdarahan post partum, menunjukkan bahwa $x^{2}$ hitung $>x^{2}$ tabel $(5,754>3,841)$, maka Ho ditolak dan Ha diterima. ini berarti ada hubungan kejadian perdarahan post partum di Rumah Sakit Umum Daerah Kabupaten Bombana pada taraf kepercayaan $95 \%(\alpha=0,05)$. Nilai $\mathrm{OR}>1$, artinya paritas $>3$ memiliki risiko 1,606 kali lebih besar mengalami perdarahan post partum dibandingkan paritas ibu antara 1-3 kali.

Menurut hasil penelitian Erna Edy (2015), Faktor risiko kejadian perdarahan post partum di RSKDIA Pertiwi Makassar, menunjukkan bahwa jarak kehamilan memilki nilai $\mathrm{OR}=0,842: 95 \% \mathrm{Cl}=0,267-$ 2,661 ) dengan tingkat kepercayaan $95 \%$. Nilai yang diperoleh menunjukkan bahwa jarak kehamilan $<2$ tahun tidak memiliki risiko untuk mengalami perdarahan post partum dan tidak bermakna secara statistik.

\section{METODE PENELITIAN}

\section{Desan, Tempat dan Waktu}

Desain: Penelitian ini merupakan penelitian kuantitatif dengan desain penelitian case control study.

Populasi: Populasi pada penelitian ini adalah semua ibu bersalin di RSKDIA Siti Fatimah Makassar, sebesar 1039 persalinan pada tahun 2018.

Sampel: Sampel dalam penelitian ini adalah semua yang mengalami perdarahan post partum dan tercatat di RSKDIA Siti Fatimah Makassar sebanyak 31 orang dan yang tidak mengalami perdarahan post partum sebanyak 31 orang dengan perbandingan 1 : 1 dengan menggunakan teknik pengambilan data purposive sampling.

Instrument: Instrumen penelitian yang digunakan untuk memperoleh data tentang faktor risiko penyebab perdarahan post partum di RSKDIA Siti Fatimah Makassar 
yaitu dengan menggunakan lembar checklist.

Pengolahan Data: Data diolah dengan Editing, Codding, Entry data, Cleaning data entry dengan SPSS versi 21.0 kemudian disajikan dalam bentuk tabel dan narasi.

Analisa Data: Univariat dan Bivariat.

\section{HASIL PENELITIAN}

Berdasarkan penelitian didapatkan hasil sebagai berikut:

a. Analisis Univariat

Tabel 1 menunjukkan bahwa dari 62 orang yang dijadikan sebagai sampel, yang mengalami perdarahan post partum sebanyak 31 orang $(50,0 \%)$ dan yang tidak mengalami perdarahan post partum sebanyak 31 orang $(50,0 \%)$.

Tabel 2 menunjukkan bahwa dari 62 orang yang dijadikan sebagai sampel, umur risiko tinggi ( $<20$ dan $>35$ tahun) sebanyak 30 orang, terdapat 19 orang $(63,3 \%)$ yang mengalami perdarahan post partum dan 11 orang $(36,7 \%)$ yang tidak mengalami perdarahan post partum. Sedangkan umur risiko rendah (20-35 tahun) sebanyak 32 orang, terdapat 12 orang $(37,5 \%)$ yang mengalami perdarahan post partum dan 20 orang $(62,5 \%)$ yang tidak mengalami perdarahan post partum.

Tabel 3 menunjukkan bahwa dari 62 orang yang dijadikan sebagai sampel, paritas risiko tinggi (Paritas $>3$ ) sebanyak 31 orang, terdapat 21 orang $(67,7 \%)$ yang mengalami perdarahan post partum dan 10 orang $(32,3 \%)$ yang tidak mengalami perdarahan post partum. Sedangkan paritas risiko rendah (Paritas 1-3) sebanyak 31 orang, terdapat 10 orang $(32,3 \%)$ yang mengalami perdarahan post partum dan 21 orang $(67,7 \%)$ yang tidak mengalami perdarahan post partum.

Tabel 4 menunjukkan bahwa dari 62 orang yang dijadikan sebagai sampel, jarak kehamilan risiko tinggi ( $<2$ Tahun) sebanyak 25 orang, terdapat 18 orang $(72,0 \%)$ yang mengalami perdarahan post partum dan 7 orang $(28,0 \%)$ yang tidak mengalami perdarahan post partum. Sedangkan jarak kehamilan risiko rendah ( $\geq 2$ Tahun) sebanyak 37 orang, terdapat 13 orang $(35,1 \%)$ yang mengalami perdarahan post partum dan 24 orang $(64,9 \%)$ yang tidak mengalami perdarahan post partum. b. Analisis Bivariat

1) Pengaruh Faktor Risiko Umur Terhadap Kejadian Perdarahan Post Partum

Tabel 5 menunjukkan bahwa dengan menggunakan uji Odds Ratio didapatkan $p=0,042<$ dari $\alpha=0,05$, ini berarti Ho ditolak dan $\mathrm{Ha}$ diterima dan nilai $O R>1$, artinya ibu yang berusia $<20$ dan $>35$ tahun memiliki risiko 2,879 kali lebih besar untuk mengalami perdarahan post partum dibandingkan dengan umur ibu antara 20-35 tahun.

2) Pengaruh Faktor Risiko Paritas Terhadap Kejadian Perdarahan Post Partum

Tabel 6 menunjukkan bahwa dengan menggunakan uji Odds Ratio didapatkan $p=0,005<$ dari $\alpha=0,05$, ini berarti Ho ditolak dan $\mathrm{Ha}$ diterima dan nilai $O R>1$, artinya ibu dengan paritas $>3$ memiliki risiko 4,410 kali lebih besar untuk mengalami perdarahan post partum dibandingkan dengan paritas ibu antara 1-3 kali.

3) Pengaruh Faktor Risiko Jarak Kehamilan Terhadap Kejadian Perdarahan Post Partum

Dengan menggunakan uji Odds Ratio didapatkan $p=$ $0,004<$ dari $\alpha=0,05$, ini berarti $\mathrm{Ho}$ ditolak dan $\mathrm{Ha}$ diterima dan nilai $\mathrm{OR}>1$, artinya ibu dengan jarak kehamilan $<2$ tahun memiliki risiko 4,747 kali lebih besar untuk mengalami perdarahan post partum dibandingkan dengan jarak kehamilan antara $\geq 2$ tahun.

\section{PEMBAHASAN}

\section{Umur}

Umur mempengaruhi proses reproduksi, ibu dikategorikan berisiko tinggi apabila hamil berusia dibawah 20 tahun karena organ reproduksinya belum matang seperti rahim belum siap untuk menerima kehamilan, jadi pada saat proses persalinan lapisan otot polos uterus tidak berkontraksi dengan baik sehingga bisa menyebabkan atonia uteri. Panggul sempit yang belum siap untuk dilalui janin pada saat proses persalinan bisa menyebabkan trauma pada jalan lahir. Sebaliknya umur diatas 35 tahun fungsi organ 
reproduksinya sudah mulai menurun hal ini dapat memicu terjadinya perdarahan dikarenakan kemampuan lapisan otot polos uterus mengalami kemunduran sehingga pembuluh darah yang terbuka tidak menutup sehingga terjadi perdarahan. (Prawirohardjo S, 2010:11)

Berdasarkan hasil uji statistic dengan menggunakan uji Odds Ratio didapatkan $p=0,042<$ dari $\alpha=0,05$, ini berarti Ho ditolak dan $\mathrm{Ha}$ diterima dan nilai $O R>1$, artinya ibu yang berumur $<20$ dan $>35$ tahun memiliki risiko 2,879 kali lebih besar mengalami perdarahan post partum dibandingkan dengan umur ibu antara 20-35 tahun

Hasil penelitian ini sejalan dengan yang dilakukan oleh Psiari Kusuma Wardani (2017) dengan judul faktor-faktor yang mempengaruhi terjadinya perdarahan pasca persalinan, menunjukkan bahwa didapatkan nilai $p=0,001$ dan OR 3,589 dengan $95 \% \mathrm{Cl}: 1,764-7,301$, hal ini berarti bahwa ibu bersalin dengan umur $<20$ dan >35 tahun berpeluang mengalami perdarahan post partum 3,589 kali lebih besar dibandingkan dengan ibu bersalin yang berumur 2035 tahun.

\section{Paritas}

Wanita dengan paritas melebihi dari 3 dikategorikan berisiko karena paritas tinggi akan mengakibatkan jaringan parut rahim dan fibrosis otototot uterus, sehingga pada saat proses persalinan akan terjadi peningkatan dehisiens parut uterus sehingga bisa menimbulkan terjadinya ruptur uteri keadaan ini akan memicu terjadinya perdarahan post partum. (Prawirohardjo S, 2010:23).

Berdasarkan hasil uji statistic dengan menggunakan uji Odds Ratio didapatkan $p=0,005<$ dari $\alpha=0,05$, ini berarti Ho ditolak dan Ha diterima dan nilai $O R>1$, artinya ibu dengan paritas $>3$ memiliki risiko 4,410 kali lebih besar untuk mengalami perdarahan post partum dibandingkan paritas ibu antara 1-3 kali.

Hasil penelitian ini sejalan dengan penelitian yang dilakukan oleh Juwita Anis Maryam (2017) dengan judul Hubungan antara paritas dan umur ibu dengan kejadian perdarahan post partum, menunjukkan bahwa nilai $x^{2}$ hitung $>x^{2}$ tabel $(5,754>3,841)$, maka Ho ditolak dan Ha diterima. ini berarti ada hubungan kejadian perdarahan post partum di Rumah Sakit Umum Daerah Kabupaten Bombana pada taraf kepercayaan $95 \%(\alpha=0,05)$. Nilai $\mathrm{OR}>1$, artinya paritas $>3$ memiliki risiko 1,606 kali lebih besar untuk mengalami perdarahan post partum dibandingkan paritas ibu antara 1-3 kali.

\section{Jarak Kehamilan}

Jarak kehamilan yang kurang dari 2 tahun dikategorikan berisiko dikarenakan organ-organ reproduksi seperti rahim belum kembali ke kondisi semula, jika terjadi kehamilan kurang dari 2 tahun maka pada saat proses persalinan berlangsung bisa mengakibatkan lapisan otot uterus tidak mampu berkontraksi sehingga pembuluh darah yang terbuka tidak dapat menutup sehingga dapat memicu perdarahan post partum. (Prawirohardjo S, 2010:29).

Berdasarkan hasil dengan menggunakan uji Odds Ratio didapatkan $p=$ $0,004<$ dari $\alpha=0,05$, ini berarti Ho ditolak dan $\mathrm{Ha}$ diterima dan nilai OR $>1$, artinya ibu dengan jarak kehamilan $<2$ tahun memiliki risiko 4,747 kali lebih besar untuk mengalami perdarahan post partum dibandingkan dengan jarak kehamilan $\geq 2$ tahun.

Hasil penelitian ini tidak sejalan yang dilakukan oleh Erna Edy (2015) dengan judul Faktor risiko kejadian perdarahan post partum di RSKDIA Pertiwi Makassar, menunjukkan bahwa jarak kehamilan memilki nilai OR=0,842 :95\% Cl=0,2672,661 ) dengan tingkat kepercayaan $95 \%$. Nilai yang diperoleh menunjukkan bahwa jarak kehamilan $<2$ tahun tidak memiliki risiko untuk mengalami perdarahan post partum dan tidak bermakna secara statistik.

\section{KESIMPULAN}

Hasil penelitian menunjukkan bahwa umur $<20$ dan $>35$ tahun terdapat hubungan dan memiliki risiko 2,879 kali lebih besar untuk mengalami perdarahan post partum dibandingkan dengan umur ibu antara 20-35 tahun. Paritas $>3$ terdapat hubungan dan memiliki risiko 4,410 kali lebih besar untuk mengalami perdarahan post partum dibandingkan dengan paritas antara 1-3 kali dan jarak kehamilan $<2$ tahun terdapat hubungan dan memiliki risiko 4,747 kali lebih besar untuk mengalami perdarahan post partum dibandingkan dengan jarak kehamilan antara $\geq 2$ tahun. 


\section{SARAN}

Diharapkan kepada ibu yang ingin hamil tidak pada umur $<20$ dan $>35$ tahun. Senantiasa rajin melakukan kunjungan kehamilan untuk mendeteksi dini kemungkinan terjadi kelainan dalam persalinan khususnya perdarahan post partum. Diharapkan kepada ibu untuk tidak memiliki paritas lebih dari 3 , ini dimaksudkan agar dapat mengurangi risiko terjadinya perdarahan post partum selanjutnya. Diharapkan kepada ibu hamil yang ingin menambah jumlah anak sebaiknya mengatur jarak kehamilan 2 tahun atau lebih dari anak sekarang atau sebelumnya guna mencegah terjadinya perdarahan post partum dan ibu yang memiliki riwayat persalinan agar senantiasa memperhatikan kehamilannya dengan melakukan pemeriksaan secara teratur, agar dapat mengurangi risiko komplikasi penyulit pada saat persalinan dan sebaiknya lebih banyak melakukan pemeriksaan antenatal care guna untuk mencegah perdarahan post partum selanjutnya.

\section{DAFTAR PUSTAKA}

Anggraini Heni dan Riansari. 2018. FaktorFaktor Yang Berhubungan Denga $n$ Perdarahan Post Partum Pada I bu Bersalin Di RSUD Pringsewu T ahun 2016. (Online), https://www.r esearchgate.net/publication/3264 74875 Faktor-Faktor Yang Berhub ungan Dengan Perdarahan Post Partum Pada Ibu Bersalin Di RSU D Pringsewu Tahun 2016. diakse s 22 November 2018

Dinas Kesehatan Provisi Sulawesi Selatan. 2016. Profil Kesehatan Provinsi S ulawesi Selatan, (Online), http://di nkes.sulselprov.go.id/assets/doku men/informasi/99acff42f874ab267 bd3a6bbeca6cafad.pdf. diakses 2 0 November 2018

Dinas Kesehatan Kota Makassar. 2015. Profil Kesehatan Kota Makassar. (Online), http://dinkeskotamakass ar.com/index.php/201702-09-09-3 $0-56$ ? download=17: profil-kesehat an-kota-makassar-Tahun-2015. diakses 20 November 2018

Departemen Kesehatan Republik Indonesia . Pusat Data dan Informasi Keseh atan Reproduksi Tahun 2018. (On line), http://www.depkes.go.id/dow nload.php?file=download/pusdatin /buletin/buletin kespro.pdf. diakses 20 November 2018

Edy Erna dan Ansar. 2015. Faktor Risiko K ejadian Perdarahan Post Partum Di RSKDIA Pertiwi Makassar Tah un 2015. (Online), http://repository .unhas.ac.id/handle/123456789/1 7156. diakses 19 November 2018

Kementrian Kesehatan Republik Indonesia. 2015. Profil Kesehatan Indonesia . Jakarta; Kemenkes Republik Ind onesia Tahun 2015. INFO DATIN Pusat Data dan Informasi Kement rian Kesehatan Republik Indenesi a. (Online), http://www.depkes.go. $\mathrm{id} /$ resources/download/pusdatin/p rofil-kesehatan-indonesia/Profil-K esehatan-Indonesia-2016.pdf. diakses 19 November 2018.

Maryam, J. A. 2017. Hubungan Antara Parit as Dan Umur Ibu Dengan Kejadia $n$ Perdarahan Post Partum Di RS UD Bombana Provinsi Sulawesi T enggara Tahun 2017. (Online), htt p://repository.poltekkes-kdi.ac.id/4 83/. diakses 20 November 2018

Manuaba, I. B. G. 2013. Gawat-Darurat Ob stetri-Ginekologi dan Obstetri-Gin ekologi Sosial Untuk Profesi Bidan. Jakarta; EGC

Notoatmodjo, S. 2010. Metode Penelitian Kesehatan. Jakarta;Rineka cipta

Prawirohardjo, S. 2016. IImu Kebidanan. Edisi Keempat Cetakan Kelima. PT Bina Pustaka; Jakarta . 2010. Ilmu Kebidanan. Edisi Keempat Cetakan Kedua. PT Bina Pustaka; Jakarta

Taber, B. Z. 2012. Kedaruratan Obstetri dan Ginekologi. Jakarta; EGC

Wardani, P. K. 2017. Faktor-Faktor Yang M empengaruhi Terjadinya Perdarah an Pasca Persalinan, (Online), htt p://repository.poltekkeskdi.ac.id/4 83/1/Final\%20Isi\%20KTI\%20Juwi ta.pdf. diakses 20 November 201 8

Woodward Vivien. 2012. Kedaruratan Pers alinan Manajemen Di Komunitas. Jakarta; EGC

World Health Organization (WHO). 2015. M aternal Mortality, http://www.who.i nt/en/news-room/factsheets/detail/maternalmortality. Diakses 19 November 2018. 
Tabel 1 Distribusi Frekuensi Kejadian Perdarahan Post Partum di RSKDIA Siti Fatimah Makassar Tahun 2018

\begin{tabular}{ccc}
\hline Perdarahan Post Partum & Frekuensi & $\begin{array}{c}\text { Persentase } \\
(\mathbf{\%})\end{array}$ \\
\hline Kasus & 31 & 50,0 \\
Kontrol & 31 & 50,0 \\
\hline Jumlah & 62 & 100,0 \\
\hline
\end{tabular}

Sumber : Data Sekunder 2018

Tabel 2 Distribusi Frekuensi Umur Ibu yang Mengalami Perdarahan Post Partum di RSKDIA Siti Fatimah Makassar Tahun 2018

\begin{tabular}{ccccc}
\hline \multirow{2}{*}{ Umur } & \multicolumn{4}{c}{ Kejadian Perdahan } \\
\cline { 2 - 5 } & $\mathbf{n}$ & $\%$ & $\mathbf{n}$ & $\%$ \\
\hline $\begin{array}{c}\text { Risiko Tinggi } \\
(<20->35 \text { tahun })\end{array}$ & 19 & 63,3 & 11 & 36,7 \\
\hline $\begin{array}{c}\text { Risiko Rendah } \\
(20-35 \text { Tahun })\end{array}$ & 12 & 37,5 & 20 & 62,5 \\
\hline Total & 31 & 50,0 & 31 & 50,0 \\
\hline
\end{tabular}

Sumber : Data Sekunder 2018

Tabel 3 Distribusi Frekuensi Paritas Ibu yang Mengalami Perdarahan Post Partum di RSKDIA Siti Fatimah Makassar Tahun 2018

\begin{tabular}{ccccc}
\hline \multirow{2}{*}{ Paritas } & \multicolumn{4}{c}{ Kejadian Perdarahan } \\
\cline { 2 - 5 } & $\mathbf{n}$ & $\%$ & $\mathbf{n}$ & Perdarahan \\
\hline $\begin{array}{c}\text { Risiko Tinggi } \\
\text { (Paritas }>3)\end{array}$ & 21 & 67,7 & 10 & 32,3 \\
\hline $\begin{array}{c}\text { Risiko Rendah } \\
\text { (Paritas 1-3) }\end{array}$ & 10 & 32,3 & 21 & 67,7 \\
\hline Total & 31 & 50,0 & 31 & 50,0 \\
\hline
\end{tabular}

Sumber : Data Sekunder 2018

Tabel 4 Distribusi Frekuensi Jarak Kehamilan Ibu yang Mengalami Perdarahan Post Partum di RSKDIA Siti Fatimah Makassar Tahun 2018

\begin{tabular}{ccccc}
\hline \multirow{2}{*}{ Jarak Kehamilan } & \multicolumn{4}{c}{ Kejadian Perdarahan } \\
\cline { 2 - 5 } & $\mathbf{n}$ & $\mathbf{\%}$ & $\mathbf{n}$ & $\%$ \\
\hline $\begin{array}{c}\text { Risiko Tinggi } \\
(<2 \text { Tahun })\end{array}$ & 18 & 72,0 & 7 & 28,0 \\
\hline $\begin{array}{c}\text { Risiko Rendah } \\
(\geq 2 \text { Tahun })\end{array}$ & 13 & 35,1 & 24 & 64,9 \\
\hline Total & 31 & 50,0 & 31 & 50,0 \\
\hline
\end{tabular}

Sumber : Data Sekunder 2018 
Tabel 5 Faktor Risiko Umur Dengan Kejadian Perdarahan Post Partum di RSKDIA Siti Fatimah Makassar Tahun 2018

\begin{tabular}{ccccccc}
\hline \multirow{2}{*}{ Umur } & \multicolumn{4}{c}{ Kejadian Perdarahan } & & \multirow{2}{*}{ OR } \\
\cline { 2 - 4 } & \multicolumn{2}{c}{ Perdarahan } & \multicolumn{2}{c}{ Tidak Perdarahan } & $\boldsymbol{p}$ & (IK95\%) \\
\cline { 2 - 4 } & $\mathbf{n}$ & $\mathbf{\%}$ & $\mathbf{n}$ & $\mathbf{\%}$ & & \\
$\begin{array}{c}\text { Risiko Tinggi } \\
(<20->35 \text { tahun })\end{array}$ & 19 & 63,3 & 11 & 36,7 & & \\
$\begin{array}{c}\text { Risiko Rendah } \\
(20-35 \text { Tahun })\end{array}$ & 12 & 37,5 & 20 & 62,5 & 0,042 & 2,879 \\
\hline Total & 31 & 50,0 & 31 & 50,0 & & \\
\hline
\end{tabular}

Sumber : Data Sekunder 2018

Tabel 6 Faktor Risiko Paritas Dengan Kejadian Perdarahan Post Partum di RSKDIA Siti Fatimah Makassar Tahun 2018

\begin{tabular}{|c|c|c|c|c|c|c|}
\hline \multirow{3}{*}{ Paritas } & \multicolumn{4}{|c|}{ Kejadian Perdarahan } & \multirow{3}{*}{$p$} & \multirow{3}{*}{$\begin{array}{c}\text { OR } \\
\text { (IK95\%) }\end{array}$} \\
\hline & \multicolumn{2}{|c|}{ Perdarahan } & \multicolumn{2}{|c|}{ Tidak Perdarahan } & & \\
\hline & $\mathbf{n}$ & $\%$ & $\mathbf{n}$ & $\%$ & & \\
\hline $\begin{array}{l}\text { Risiko Tinggi } \\
(\text { Paritas >3) }\end{array}$ & 21 & 67,7 & 10 & 32,3 & & \\
\hline $\begin{array}{c}\text { Risiko Rendah } \\
\text { (Paritas 1-3) }\end{array}$ & 10 & 32,3 & 21 & 67,7 & 0,005 & 4,410 \\
\hline Total & 31 & 50,0 & 31 & 50,0 & & \\
\hline
\end{tabular}

Sumber : Data Sekunder 2018

Tabel 7 Faktor Risiko Jarak Kehamilan Dengan Kejadian Perdarahan Post Partum di RSKDIA Siti Fatimah Makassar Tahun 2018

\begin{tabular}{|c|c|c|c|c|c|c|}
\hline \multirow{3}{*}{ Jarak Kehamilan } & \multicolumn{4}{|c|}{ Kejadian Perdarahan } & \multirow{3}{*}{$p$} & \multirow{3}{*}{$\begin{array}{c}\text { OR } \\
\text { (IK95\%) }\end{array}$} \\
\hline & \multicolumn{2}{|c|}{ Perdarahan } & \multicolumn{2}{|c|}{ Tidak Perdarahan } & & \\
\hline & $\mathrm{n}$ & $\%$ & $n$ & $\%$ & & \\
\hline $\begin{array}{l}\text { Risiko Tinggi } \\
\text { (<2 Tahun) }\end{array}$ & 18 & 72,0 & 7 & 28,0 & & \\
\hline $\begin{array}{l}\text { Risiko Rendah } \\
\text { (>2 Tahun) }\end{array}$ & 13 & 35,1 & 24 & 64,9 & 0,004 & 4,747 \\
\hline Total & 31 & 50,0 & 31 & 50,0 & & \\
\hline
\end{tabular}

Sumber : Data Sekunder 2018 